\title{
Effect of Starch Nanocrystals on the Properties of Low Density Polyethylene/Thermoplastic Starch Blends
}

\author{
Saliha Chaoui \\ Department of Chemical Engineering \\ University Ferhat Abbas of Setif 1 \\ Setif, Algeria \\ salihachaoui@yahoo.fr \\ Abdelhak Hellati \\ Faculty of Science and Technology \\ Med Bachir El Ibrahimi University \\ Bordj Bou Arreridj, Algeria \\ hellati_abdelhak@yahoo.fr
}

\author{
Dalila Smail \\ Department of Chemical Engineering \\ University Ferhat Abbas of Setif 1 \\ Setif, Algeria \\ dalila.smail@yahoo.fr \\ Djafer Benachour \\ Department of Ehemical Engineering \\ University Ferhat Abbas of Setif 1 \\ Setif, Algeria \\ bendjafer@univ-setif.dz
}

\begin{abstract}
In this study, Low Density Polyethylene (LDPE) and Thermoplastic Starch (TPS) reinforced with different amounts of Starch Nanocrystals (SNCs) with and without Dicumyl Peroxide (DCP) were blended in an internal mixer. The XRD results showed that crystallinity decreases with increasing SNC content with and without DCP. Tensile test results showed that elongation at breaking, tensile strength, and elastic modulus are lower than that of neat LDPE, whereas, the elastic modulus for the LDPE/TPS/SNC5\%/DCP is higher than that of LDPE. AFM showed a decrease in the roughness of the surface after the addition of SNC and the surface become less rough after DCP addition.
\end{abstract}

Keywords-nanocomposites; thermoplastic starch; LDPE; starch nanocrystals; DCP

\section{INTRODUCTION}

Environmental pollution from consumed polymers has become a serious global concern. This type of pollution comes mainly from plastic waste, particularly from packaging materials, offset plastic bags, bottles, cups, etc. [1]. Considerable efforts are being directed towards developing biodegradable composites using renewable resources in an attempt to replace petroleum-based plastics with more sustainable materials $[2,3]$. Starch is one of the most promising materials that can remedy these problems and improve the properties of plastic packaging materials. Experience has shown that it is possible to transform native starch into thermoplastic resin products under deformation and plasticization conditions. Unfortunately, Thermoplastic Starch (TPS) is a very hydrophilic material with limited performance. To overcome this difficulty and maintain its biodegradability, one strategy is to combine plasticized starch with another biodegradable polymer [4]. To decrease the brittleness of biodegradable plastics, another approach is to blend thermoplastic starch with synthetic materials such as LLDPE, HDPE, PP and others. Synthetic materials have advantages such as high mechanical properties. Polyethylene (PE) is one of the most widely produced non-biodegradable polymers, and different types of PE are commonly used in many fields. The main sectors are food packaging products and garbage bags [5]. Biodegradable plastics made from blends of TPS/synthetic materials have little compatibility with hydrophilic starch and hydrophobic synthetic polymers. In order to achieve compatibility between these two fractions, compatibilizers can be added to reduce the interfacial energy and homogenize the polar starch with the synthetic polymer. Compatibilizers can act by reactive process, for example grafting techniques or hydrogen bonding based on the polarity of the material. Among these, maleic anhydride, succinic anhydride and acid acrylate are the most widely used compatibilizers [6]. With the development of biodegradable materials, polysaccharides and nanocrystals/nanoparticles in particular, are attracting more scientific interest. These materials are among the more promising sources for the production of nanoparticles mainly due to their semi-crystalline structure. Starch is a promising candidate for the production of nanoparticles because it has a semi-crystalline structure that confers some interesting properties [2]. Over the last decade, Starch Nanocrystals (SNCs) have attracted a growing interest due to not only their nano-scaled size but also their renewable and biodegradable nature. The availability of reactive hydroxyl groups on the surface of the freeze-dried powders was essential for the chemical modification of the SNCs. Most studies have only focused on the use of SNCs as reinforcing agents for polar polymers. SNCs have been used as filler for latex of Natural Rubbers (NRs). It is shown that up to a content of $20 \mathrm{wt} \%$ this new filler presents the advantage to reinforce NRs without 
decreasing significantly the elongation at break of the material [7]. SNCs prepared by acid hydrolysis of native granules were used as a reinforcing agent in a thermoplastic waxy maize starch matrix plasticized with glycerol. SNCs have showed a reinforcing effect which can be attributed to strong filler/filler and filler/matrix interactions due to the establishment of hydrogen bonding. The presence of SNCs slows down the recrystallization of the matrix during aging in humid atmosphere [8]. Poly( $\hat{I} \mu$-caprolactone) (PCL) was grafted to the surface of SNCs via microwave-assisted ring-opening. The resultant nanoparticles were then incorporated into a poly(lactic acid) matrix to produce fully-biodegradable nanocomposites. A loading level of $5 \mathrm{wt} \%$ SNC-g-PCL resulted in simultaneous enhancements of strength and elongation. The SNC-g-PCL self-aggregated as rubbery microparticles to enhance elongation. Meanwhile, the grafted PCL chains were miscible with PLA and formed a stress-transferring interface to the SNCs, providing a reinforcing function [9]. Thermoplastic Starch (TPS) films were prepared with normal maize starch matrix using glycerol, D-isosorbide and 1,3-propanediol as plasticizers. TPS nanocomposite films were prepared using normal maize starch matrix plasticized with glycerol filled by Waxy Starch Nanocrystals (WSNCs) and Cellulose Nanocrystals (CNCs). The results suggested that effective interfacial hydrogen bonding interactions were achieved by extrusion/compression processing, obtaining tensile strength, strain at break and Young's modulus increments higher than $100 \%$ for nanocomposites reinforced by only $1 \mathrm{wt} \%$ of polysaccharide nanocrystals, either with only WSNC or with combinations of WSNCs/CNCs in different ratios [10].

There are only a few studies available on the use of SNCs as reinforcing agents for nonpolar polymers, especially for polyolefins. Three types of starch were converted into nanoparticles for the purpose of modifying the matrix of LowDensity Polyethylene (LDPE) in order to enhance its biodegradability. Authors in [11] outline the process of the synthesis and characterization of starch nanoparticles from three different starch sources. The utilized kinds of starch were: Zea mays (corn), Ipomoea batatas (potato), and Manihot esculenta (cassava). In [12], starch nanoparticles (SNPs) were synthesized and used as fillers to prepare high density Polyethylene (PE) composites by in situ polymerization. The effect of these particles on thermal degradation, isothermal and nonisothermal crystallization, and photodegradation of PE has been studied. SNPs decreased the thermal degradation temperature of PE and increased the relative crystallinity and crystallization rate under isothermal conditions. The composite $\mathrm{PE} / \mathrm{SNP}$ showed the nucleating effect of SNPs. This nucleating agent effect was confirmed by nonisothermal crystallizations as composites presented higher crystallization temperatures than neat PE. The photodegradation tests showed that NPs promoted the polymer degradation by forming cavities at the NP/PE interface.

Based in [12], where PE/SNPs in situ polymerization was investigated, we aim to determine the influence of various amounts of SNC incorporation in LDPE/TPS blends in the presence of a low amount of DCP. LDPE/TPS blend has mediocre mechanical properties, the DCP is added to create some crosslinking in the LDPE matrix and therefore to overcome the weakness of LDPE/TPS composites. The structural, morphological, and tensile properties of different samples were examined using FTIR analysis, X-Ray Diffraction (XRD), tensile properties, and AFM imaging. Until now, no scientifics work has been focused on the study of the LDPE/TPS/SNC/DCP system.

\section{MATERIALS AND METHODS}

\section{A. Materials}

The materials studied were LDPE supplied by SABIC society (Saudia Arabia), with a Melt Flow Index (MFI) of $0.8 \mathrm{~g} / 10 \mathrm{~min}$ at $190^{\circ} \mathrm{C}$ and a density of $0.92 \mathrm{~g} / \mathrm{cm}^{3}$. Corn starch (supplied by Roquette firm, with a density of $1.46 \mathrm{~g} / \mathrm{cm}^{3}$ and $13 \mu \mathrm{m}$ average size) initially composed of $23 \%$ amylose and $77 \%$ amylopectine, was used as degradable component. Glycerol (with a density of $1.25 \mathrm{~g} / \mathrm{cm}^{3}$ ) was used as plastizer for starch. The peroxide used is DCP provided by ACROS, Belgium. It is a white powder, and its decomposition temperature is $140^{\circ} \mathrm{C}$.

\section{B. Preparation of Thermoplastic Starch (TPS)}

Plastized Starch (PLS) was prepared according to the following experimental protocol [13]: PLS formulation used was composed of $23 \mathrm{wt} \%$ of glycerol, $23 \mathrm{wt} \%$ of distilled water and $54 \mathrm{wt} \%$ of starch. First, the starch was introduced into a turbo mixer, and then water was gradually added during stirring. In the second step, glycerol was gradually added during stirring. After the complete addition of glycerol, the mixture was mixed at high speed to obtain a homogeneous dispersion. The resulting mixture was placed in an oven at $170^{\circ} \mathrm{C}$ for 40 minutes in order to evaporate water and to facilitate plasticizer diffusion into starch grains. TPS was prepared by melting processing in an internal mixer at $140^{\circ} \mathrm{C}$.

\section{Preparation of Starch Nanocrystals}

SNCs were prepared by acid hydrolysis. Native starch $(147 \mathrm{~g})$ was dispersed in a 11 sulfuric acid $\left(\mathrm{H}_{2} \mathrm{SO} 4\right)$ solution $(3.16 \mathrm{M})$ at $300 \mathrm{rpm}$ and $40^{\circ} \mathrm{C}$. After three days of hydrolysis, the process was finished. The insoluble residue was washed by successive centrifugations with distilled water for $10 \mathrm{~min}$ at $10000 \mathrm{rpm}$ until neutral $\mathrm{pH}$ was obtained. The precipitate containing starch crystals was dried and crushed [14].

\section{Sample Preparation}

LDPE, TPS, SNCs and DCP were mixed together as dry mixtures. They were melt blended in one step in an internal mixer (PLASTI-CORDER) at $140^{\circ} \mathrm{C}$ with rotor speed of 50rpm for $10 \mathrm{~min}$. TPS and DCP contents were fixed at $30 \%$ and $0.2 \%$ $(w t \%)$ respectively for all formulations. SNC amount varied from 1 , to 3 and $5 \mathrm{wt} \%$. The LDPE/TPS/SNC nanocomposites were prepared with different concentrations of SNCs with and without DCP. The various studied formulations are summarized in Table I.

\section{E. Films Preparation}

Concerning the different characterizations, after preheating and degassing, the samples are compressed at $140^{\circ} \mathrm{C}$ for $5 \mathrm{~min}$ using a POLYLAB hydraulic press. The obtained films were 
cooled to ambient temperature. The thickness of the films was $-0.2 \mathrm{~mm}$.

TABLE I. SAMPLE CODES AND COMPOSITIONS

\begin{tabular}{|c|c|c|c|c|}
\hline Sample code & $\begin{array}{c}\text { LDPE } \\
(\mathbf{w t} \%)\end{array}$ & $\begin{array}{c}\text { TPS } \\
(\mathbf{w t} \%)\end{array}$ & $\begin{array}{c}\text { SNC } \\
(\mathbf{w t} \%)\end{array}$ & $\begin{array}{c}\text { DCP } \\
(\mathbf{w t} \%)\end{array}$ \\
\hline LDPE & 100 & 0 & 0 & 0 \\
\hline LDPE/TPS & 70 & 30 & 0 & 0 \\
\hline LDPE/TPS/SNC\% & 69 & 30 & 1 & 0 \\
\hline LDPE/TPS/SNC3\% & 67 & 30 & 3 & 0 \\
\hline LDPE/TPS/SNC5\% & 65 & 30 & 5 & 0 \\
\hline LDPE/TPS/SNC1\%/DCP & 68.8 & 30 & 1 & 0.2 \\
\hline LDPE/TPS/SNC3\%/DCP & 66.8 & 30 & 3 & 0.2 \\
\hline LDPE/TPS/SNC5\%/DCP & 64.8 & 30 & 5 & 0.2 \\
\hline
\end{tabular}

\section{F. Characterization}

\section{1) FTIR Analysis}

The absorbance spectrums (FTIR) of prepared films were recorded in a Perkin-Elmer Fourier transform infrared spectrometer working in transmission and reflection. The spectra were obtained with a resolution of $4 \mathrm{~cm}^{-1}$ for field study from 4000 to $450 \mathrm{~cm}^{-1}$.

\section{2) Water Absorption}

Water uptake was carried out on specimens using square films $(1 \mathrm{~cm} \times 1 \mathrm{~cm})$ with around $0.2 \mathrm{~mm}$ thickness. After being weighed, the samples were immersed in distilled water. At different times, they were removed from water, their surface was dried on paper, and the amount of the absorbed water by the samples was determined by weighting them periodically, until equilibrium of a constant weight was obtained. The water uptake (W\%) was given by:

$$
W(\%)=\left(\frac{W_{t}-W_{1}}{W_{t}}\right) \times 100
$$

where, $W_{t}$ is the weight of the sample at time $(t)$ after immersion, and $W_{0}$ its initial weight before immersion.

\section{3) XRD Analysis}

All the film samples were analyzed by XRD using a Philips diffractometer. The following conditions were employed: $\mathrm{Cu} \mathrm{K}$ radiation, angular range $(2 \theta) 2^{\circ}-43^{\circ}$, and scan rate $0.05 \%$. Crystallinity was calculated by dividing the area of crystalline phase with the total area of the XRD diffractograms of the sample.

\section{4) Mechanical Properties}

The samples were prepared for tensile tests according to ASTM 638-72. Tensile strength, Young's modulus, and elongation at break were measured. The tests were performed at a cross-head speed of $20 \mathrm{~mm} / \mathrm{min}$ using an MTS model LPS.504 machine.

\section{5) Atomic Force Microscopy Imaging}

Atomic Force Microscopy (AFM) was also used to explore the surface state of the resulting samples by imaging their morphologies. This characterization was carried out using a pacific Nanotechnology type atomic force microscope in noncontact mode.

\section{RESULTS AND DISCUSSION}

\section{A. FTIR Analysis}

Figures 1 and 2 show the FTIR spectra of pure LDPE, LDPE/TPS blend and LDPE/TPS/SNC nanocomposites at different SNC contents with and without DCP. LDPE spectra show characteristic bands at $2980 \mathrm{~cm}^{-1}$ and $2830 \mathrm{~cm}^{-1}$ which correspond to asymmetric and symmetric $\mathrm{C}-\mathrm{H}$ stretching vibrations respectively (Figure 1). The sharp peak at $1462 \mathrm{~cm}^{-1}$ and the peak at $720 \mathrm{~cm}^{-1}$ also indicate the $\mathrm{C}-\mathrm{H}$ bending and $\mathrm{C}-\mathrm{C}$ rocking deformation vibrations [15]. LDPE/TPS spectra show characteristic bands of saccharides localized between 950 and $1200 \mathrm{~cm}^{-1}$. They are characterized by stretching vibrations of C$\mathrm{C}$ and $\mathrm{C}-\mathrm{O}$ bands present in amylose and amylopectin [16]. A wide band can be seen between 3100 and $3600 \mathrm{~cm}^{-1}$ corresponding to the vibration of $\mathrm{O}-\mathrm{H}$ group [16]. A peak localized around $1650 \mathrm{~cm}^{-1}$ is attributed to stretching vibrations of the $\mathrm{O}-\mathrm{H}$ bond of absorbed water. In the FTIR spectra of LDPE/TPS/SNC nanocomposites at different contents of SNC without DCP, all characteristic peaks of LDPE and starch were observed (Figure1). The intensities of characteristic peaks of the LDPE were decreased by increasing SNC content in the nanocomposites without DCP. In Figure 2(a), a decrease in the intensities of LDPE peaks was observed. The characteristic peaks of DCP $\left(1700-1740 \mathrm{~cm}^{-1}\right)$ did not appear on the nanocomposite spectra, maybe due to the low concentration of DCP $(0.2 \mathrm{wt} \%)$. No displacement of the peaks was observed for all nanocomposites.

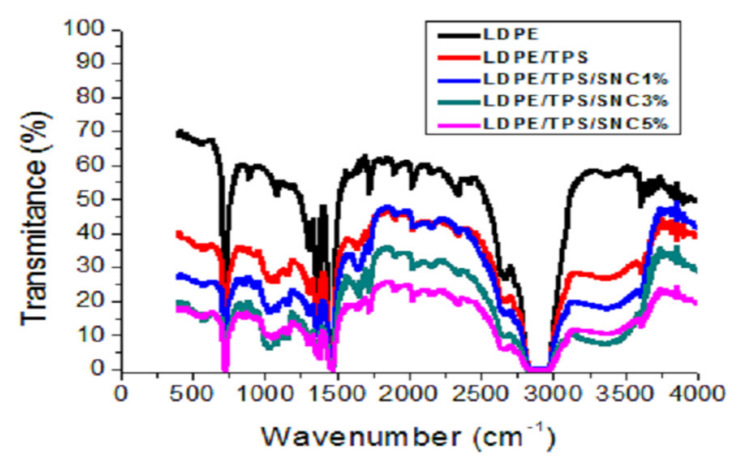

Fig. 1. FTIR spectra of LDPE, LDPE/TPS blend and LDPE/TPS/SNC nanocomposites without DCP.

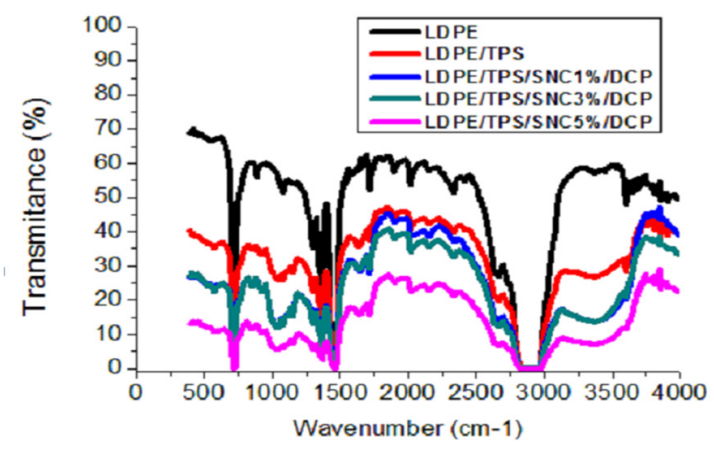

Fig. 2. FTIR spectra of LDPE, LDPE/starch blend and LDPE/TPS/SNC nanocomposites with DCP. 


\section{B. Water Abortion}

Figure 3 shows the evolution of swelling ratio $(W \%)$ for the LDPE/TPS blend and LDPE/TPS/SNC nanocomposites at 1, 3 and $5 \mathrm{wt} \%$ of SNCs with and without DCP.

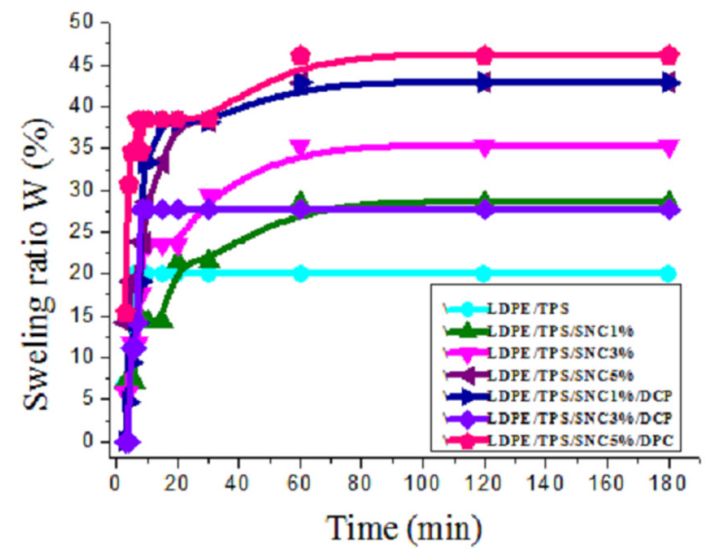

Fig. 3. Water uptake ratio of the LDPE/TPS blend, LDPE/TPS/SNC nanocomposites with and without DCP.

The kinetics of water uptake for all samples increased linearly with time in the initial step until the equilibrium was reached at about $20 \mathrm{~min}$ after the immersion in distilled water. LDPE/TPS blend showed the lower water uptake compared to the other samples. This behavior is due to the hydrophilic nature of TPS, which is responsible for the water absorption in the blend. Water molecules interacted with the hydroxyl groups of starch and saturated the surface through voids at a short swelling time [17]. The water uptake of the LDPE/TPS/SNC nanocomposites increased at equilibrium state compared to the LDPE/TPS blend with increasing SNC content. This was probably caused by the increasing starch content, since the SNCs are starch-based. The percentage of water uptake for the LDPE/TPS/SNC/DCP nanocomposites increased more than those without DCP. This can be explained by the increasing of the voids caused by DCP after chains scission and crosslinking.

\section{XRD Analysis}

Figure 4 shows the diffractograms of native starch SNCs. Native starch showed crystalline pattern $\mathbf{A}$ with three strong peaks $(2 \theta)$ at $15.4^{\circ}, 17.1^{\circ}$, and $23.3^{\circ}$. After acid hydrolysis treatment, there were significant changes in the diffraction pattern of SNCs [1]. The results showed that SNC peaks have higher intensity than those of native starch with a new peak appearing at $26.8^{\circ}$. The higher intensity of diffraction peak indicates that SNC crystallinity has been increased by acid hydrolysis [18]. The crystallinity values (determined from the XRD patterns) were estimated as $56 \%$ and $62 \%$ for native starch and SNCs respectively [19]. Figure 5 shows the X-ray diffractograms of neat LDPE, LDPE/TPS blend and the LDPE/TPS/SNC nanocomposites at 1, 3 and $5 \mathrm{wt} \%$ of SNCs without DCP. The X-ray diffractogram of the LDPE reveals a crystal lattice showing the diffraction characteristic peaks at the $2 \theta$ equal to $21.56^{\circ}$ and $23.87^{\circ}$. The superposition of the LDPE spectrum with those of LDPE/TPS blend and the nanocomposites containing 1,3 , and $5 \mathrm{wt} \%$ of SNC, showed a diminution in the intensity of characteristics peaks of LDPE with increased amounts of SNCs. Table II shows a decrease in the degree of crystallinity for LDPE/TPS /SNC by increasing SNC content indicating that SNC particles do not act as nucleating agents. In contrast to our result, an increase in crystallinity of LDPE was observed for LDPE/SNC composite after SNC addition using in situ polymerization[12].

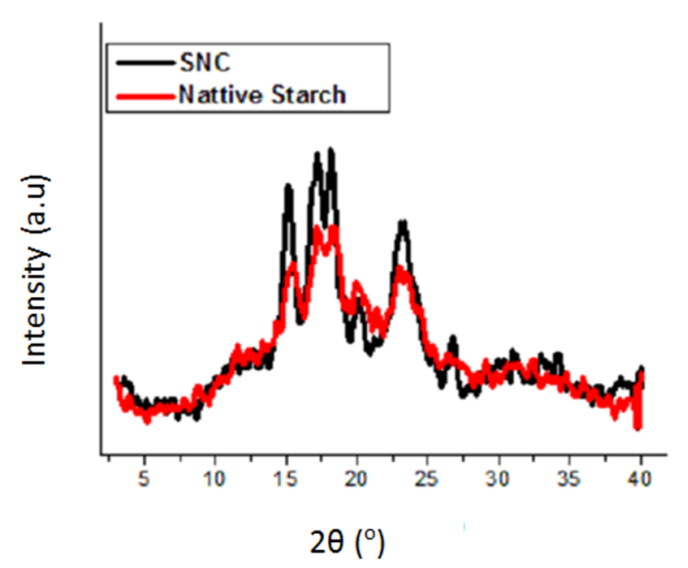

Fig. 4. X-ray diffractograms of native starch and its SNCs.

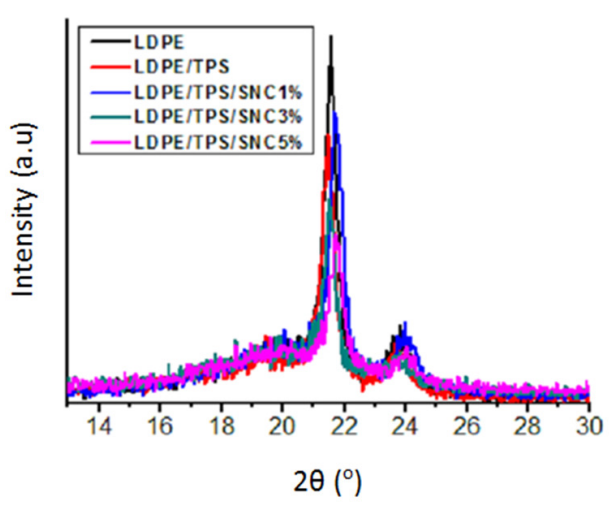

Fig. 5. X-ray diffractograms of LDPE/TPS blend and LDPE/TPS/SNC nanocomposites at various SNC contents without DCP.

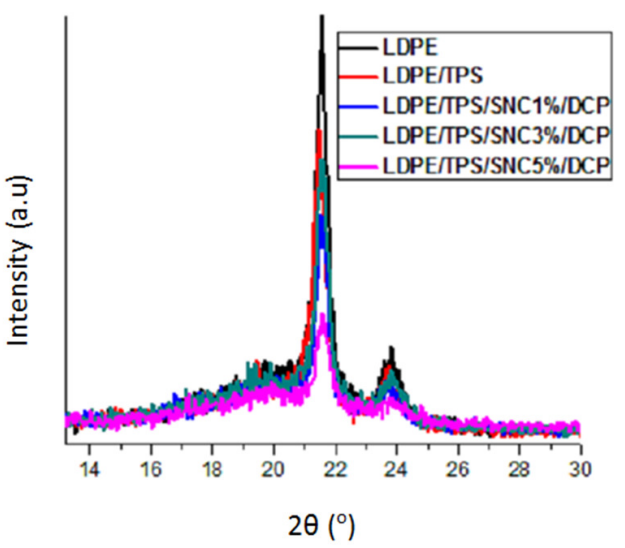

Fig. 6. X-ray diffractograms of LDPE/TPS blend and LDPE/TPS/SNC nanocomposites at various SNC content with DCP. 
Figure 6 shows the X-ray diffractograms of LDPE/TPS/SNC/DCP nanocomposites at different SNC levels in presence of DCP. A decrease in the intensity of characteristics peaks of LDPE is observed after the DCP addition. A diminution in the degree of crystallinity is also observed after the DCP addition (Table II). This is probably due to some crosslinking of LDPE by DCP, which can be considered as deficiencies center and hindered folding of macromolecular chains $[17,18]$. This behavior led to a decrease in crystallinity. This behavior is also observed in [20$22]$.

TABLE II. CRYSTALLINITY

\begin{tabular}{|c|c|}
\hline Sample code & Crystallinity \\
\hline LDPE & 54 \\
\hline LDPE/TPS & 50 \\
\hline LDPE/TPS/SNC1\% & 50 \\
\hline PEBD/TPS/SNC3\% & 40 \\
\hline PEBD/TPS/SNC5\% & 48 \\
\hline PEBD/TPS/SNC1\%/DCP & 45 \\
\hline PEBD/TPS/SNC3\%/DCP & 43 \\
\hline PEBD/TPS/SNC5\%/DCP & 34 \\
\hline
\end{tabular}

\section{Tensile Properties}

Figures 7 and 8 show the evolution of elongation at break and of the tensile strength of the LDPE/TPS blend and LDPE/TPS/SNC nanocomposites as a function of SNC amount with and without DCP. LDPE/TPS blend exhibited a decrease in tensile properties compared to neat LDPE. This can be explained by the incompatibility between LDPE and TPS caused by the difference in their hydrophobic and hydrophilic character respectively. A significant decrease in tensile strength and elongation at break was observed for LDPE/TPS/SNC nanocomposites at 1,3 , and $5 \mathrm{wt} \% \mathrm{SNC}$ with and without DCP compared to pure LDPE (Figures 7-8). This result (summarized in Table II) suggests that SNC did not act as nanocomposite reinforcing agent. According to [12], SNC can create cavities in the LDPE due to the difference in the results in the deterioration of mechanical properties. This result confirmed the crystallinity decrease (measured by DRX). The addition of DCP for the LDPE/TPS/SNC/DCP nanocomposites at different amounts of SNC (Figures 7-8) added more cavities which are attributed to some crosslinking provoked by DCP. These cavities lead to the diminution of crystallinity and therefore to the decrease of tensile properties [23]. Figure 9 shows the effect of SNC content on the elastic modulus of LDPE/TPS/SNC nanocomposites at different SNC amounts, with and without DCP. It could be noted that the elastic modulus decreases at $1 \mathrm{wt} \%$ of SNC and increases at $3 \mathrm{wt} \%$, but remained lower than LDPE modulus, whereas at $5 \mathrm{wt} \%$ of SNC it is slightly superior to that of pure LDPE. The values of elastic modulus for all nanocomposites with DCP are slightly superior to those without DCP. This increase in the elastic modulus for the LDPE/TPS/SNC5\%/DCP nanocomposite can be related to the SNC agglomeration [24] (because of the high amount of SNC (5wt\%) ). Filler-filler interactions become more significant than the filler-matrix interactions [25] or the reduction in polymer chains mobility in the presence of the filler [26].

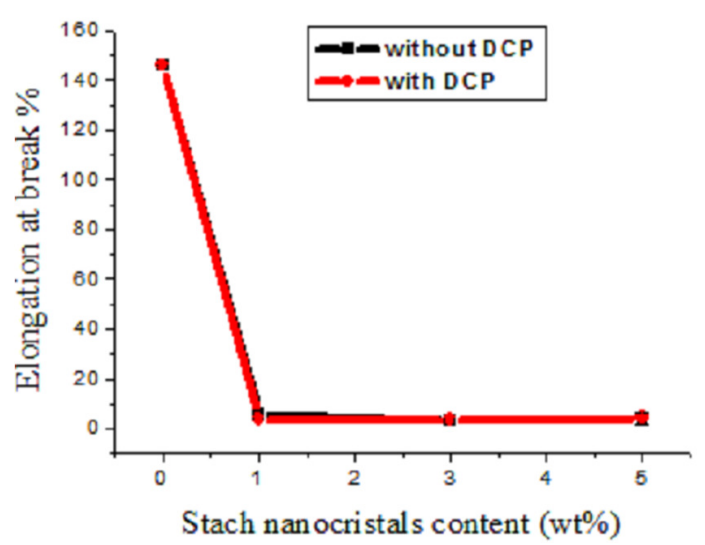

Fig. 7. Elongation at break evolution of LDPE and LDPE/TPS/SNC nanocomposites at different SNC contents with and without DCP.

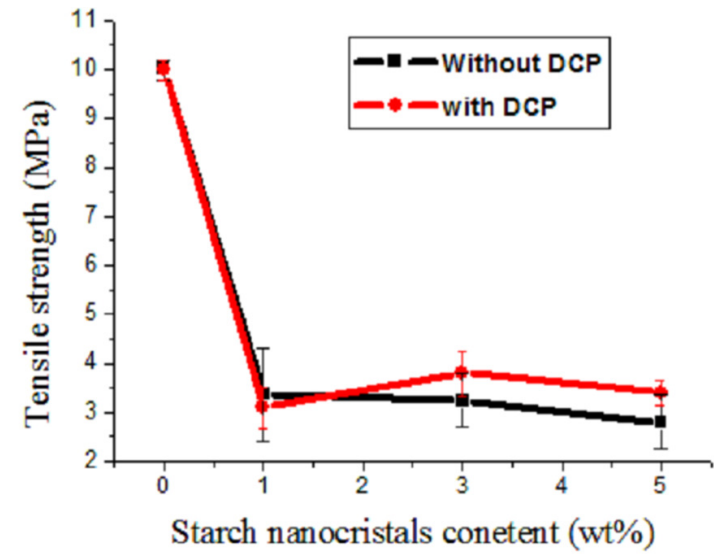

Fig. 8. Tensile strength evolutions of LDPE and and LDPE/TPS/SNC nanocomposites at different SNC content with and without DCP.

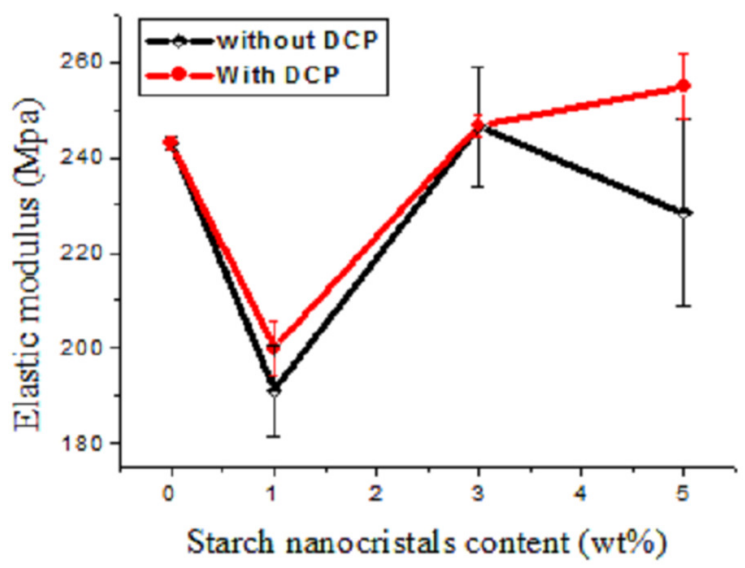

Fig. 9. Elastic modulus evolution of LDPE and LDPE/TPS/SNC nanocomposites at different SNC content with and without DCP.

\section{E. AFM Imaging}

The morphological aspect was evaluated by AFM. Figure 10 shows the surface images of neat LDPE, LDPE/TPS/SNC5 
nanocomposite of $5 \mathrm{wt} \% \quad \mathrm{SNC}$ without $\mathrm{DCP}$ and LDPE/TPS/SNC5/DCP nanocomposites of $5 \mathrm{wt} \%$ SNC with DCP. The film surface of LDPE is rigorous and dense which appeared well on the surface (Figure 10(a)). As the TPS and SNCs were added to LDPE for the nanocomposite LDPE/TPS/SNC5\% (Figure 10(b)) the density of roughness decreased. Since the SNCs present a platelet -like- shape, a packet of sticks is observed on the film surface. The presence of DCP in the nanocomposite LDPE/TPS/SNC5/DCP (Figure 10(c)) makes the surface smooth. The decrease in the film surface roughness in the presence of SNC and DCP may be caused by the decrease of density and crystallinity (measured by XRD) and was confirmed by the decrease in the tensile properties.

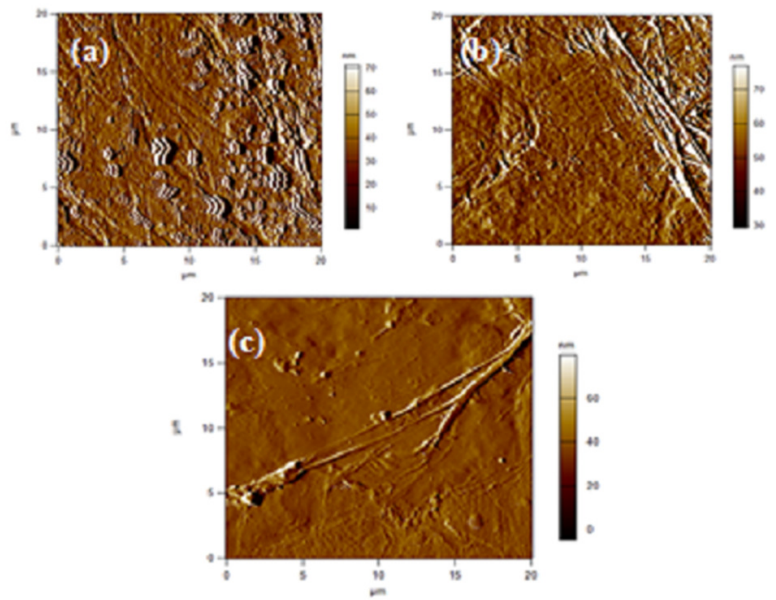

Fig. 10. AFM images of the surface of (a) neat LDPE, (b) LDPE/TPS/SNC5 nanocomposite with $5 \%$ of SNC, and (c) LDPE/TPS/SNC5/DCP nanocomposite with $5 \%$ of SNC in the presence $f$ DCP.

\section{CONCLUSION}

In this work, LDPE/TPS/SNC nanocomposites reinforced with various amounts of SNC with and without DCP were prepared with an internal mixer. Structural tests showed that the crystallinity of LDPE/TPS/SNC nanocomposites decreased with increasing SNC content and decreased even more after DCP addition. Water uptake test showed an increase in water absorption by increasing SNC amount, whereas the DCP addition provoked more increasing of this property. FTIR analysis showed a decrease in the intensity peaks of LDPE/TPS/SNC with increasing SNC content with and without DCP. The AFM showed that the SNC and DCP decreased the roughness of the nanocomposite surface. Tensile results showed that the elongation at break of the nanocomposites decreases sharply with increasing SNC content. The same behavior was noted in tensile strength and elastic modulus, whereas Young's modulus of the LDPE/TPS/SNC5\%/DCP was slightly higher than that of the pure LDPE. AFM imaging showed a decrease in roughness and surface density after the addition of SNC and DCP.

\section{REFERENCES}

[1] K. Piyada, S. Waranyou, and W. Thawien, "Mechanical, thermal and structural properties of rice starch films reinforced with rice starch nanocrystals," International Food Research Journal, vol. 20, no. 1, pp. 439-449, Feb. 2013.

[2] P. M. Visakh, "Chapter 1 Starch: State-of-the-Art, New Challenges and Opportunities," in Starch-based Blends, Composites and Nanocomposites, P. M. Visakh, Y. Long, Eds, Royal Society of Chemistry, 2015, ch. 1, pp. 1-16, doi: 10.1039/9781782622796-00001.

[3] D. Le Corre, J. Bras, and A. Dufresne, "Starch Nanoparticles: A Review," Biomacromolecules, vol. 11, no. 5, pp. 1139-1153, May 2010, doi: $10.1021 / \mathrm{bm} 901428 \mathrm{y}$.

[4] E. Schwach and L. Averous, "Starch-based biodegradable blends: morphology and interface properties," Polymer International, vol. 53, no. 12, pp. 2115-2124, 2004, doi: 10.1002/pi.1636.

[5] A. S. Alghamdi, "Creep Resistance of Polyethylene-based Nanocomposites," Engineering, Technology \& Applied Science Research, vol. 9, no. 4, pp. 4367-4370, Aug. 2019.

[6] Waryat, M. Romli, A. Suryani, I. Yuliasih, and S. Johan, "Using of a Compatibilizer to Improve Morphological , Physical and Mechanical Properties of Biodegradable Plastic From Thermoplastic Starch / LLDPE Blends," International Journal of Engineering \& Technology, vol. 13, no. 1, pp. 115-122, Feb. 2013.

[7] H. Angellier, S. Molina-Boisseau, and A. Dufresne, "Mechanical Properties of Waxy Maize Starch Nanocrystal Reinforced Natural Rubber," Macromolecules, vol. 38, no. 22, pp. 9161-9170, Nov. 2005, doi: $10.1021 / \mathrm{ma} 0512399$.

[8] H. Angellier, S. Molina-Boisseau, P. Dole, and A. Dufresne, "Thermoplastic starch-waxy maize starch nanocrystals nanocomposites," Biomacromolecules, vol. 7, no. 2, pp. 531-539, Feb. 2006, doi: $10.1021 / \mathrm{bm} 050797 \mathrm{~s}$

[9] J. Yu, F. Ai, A. Dufresne, S. Gao, J. Huang, and P. R. Chang, "Structure and Mechanical Properties of Poly(lactic acid) Filled with (Starch nanocrystal)-graft-poly(e-caprolactone)," Macromolecular Materials and Engineering, vol. 293, no. 9, pp. 763-770, 2008, doi: 10.1002/mame. 200800134 .

[10] K. Gonzalez, L. Iturriaga, A. Gonzalez, A. Eceiza, and N. Gabilondo, "Improving mechanical and barrier properties of thermoplastic starch and polysaccharide nanocrystals nanocomposites," European Polymer Journal, vol. 123, Jan. 2020, Art no. 109415, doi: 10.1016/j.eurpolymj.2019.109415.

[11] A. A. Abioye et al., "Synthesis and Characterization of Selected Starch Nanoparticles as Matrix Reinforcements for Low Density Polyethylene," Journal of Physics: Conference Series, vol. 1378, Dec. 2019, Art no. 042070, doi: 10.1088/1742-6596/1378/4/042070.

[12] N. Amigo et al., "Effect of starch nanoparticles on the crystallization kinetics and photodegradation of high density polyethylene," Composites Part B: Engineering, vol. 174, Oct. 2019, Art. no. 106979, doi: 10.1016/j.compositesb.2019.106979.

[13] F. Chivrac, E. Pollet, M. Schmutz, and L. Averous, "New approach to elaborate exfoliated starch-based nanobiocomposites," Biomacromolecules, vol. 9, no. 3, pp. 896-900, Mar. 2008, doi: $10.1021 / \mathrm{bm} 7012668$.

[14] H. Angellier, S. Molina-Boisseau, M. N. Belgacem, and A. Dufresne, "Surface chemical modification of waxy maize starch nanocrystals," Langmuir, vol. 21, no. 6, pp. 2425-2433, Mar. 2005, doi: 10.1021/la047530j.

[15] U. Alkan, et al., "Electrical and Mechanical Properties of LDPE/PANI Composites", Journal of Nanoelectronics and Optoelectronics, vol. 11, no.4, pp. 401-406, Jun. 2016

[16] J. Korol, J. Lenża, and K. Formela, "Manufacture and research of TPS/PE biocomposites properties," Composites Part B: Engineering, vol. $68, \quad$ pp. 310-316, Jan. 2015, doi: 10.1016/j.compositesb.2014.08.045.

[17] R. A. Majid, H. Ismail, and R. M. Taib, "Effects of PE-g-MA on Tensile Properties, Morphology and Water Absorption of LDPE/Thermoplastic Sago Starch Blends," Polymer-Plastics Technology and Engineering, vol. 48, no. 9, pp. 919-924, Aug. 2009 
[18] J. Saeng-on and D. Aht-Ong, "Production of Starch Nanocrystals from Agricultural Materials Using Mild Acid Hydrolysis Method: Optimization and Characterization," Polymers from Renewable Resources, vol. 8, no. 3, pp. 91-116, Aug. 2017, doi: $10.1177 / 204124791700800302$.

[19] H. Yu, Q. Fang, Y. Cao, and Z. Liu, "Effect of HCl on Starch Structure and Properties of Starch-based Wood Adhesives," BioResources, vol. 11, no. 1, pp. 1721-1728, Jan. 2016.

[20] V. D. Ramos, H. M. da Costa, A. O. Pereira, M. C. G. Rocha, and A. de S.Gomes, "Study of low concentrations of dicumyl peroxide on the molecular structure modification of LLDPE by reactive extrusion," Polymer Testing, vol. 23, no. 8, pp. 949-955, Dec. 2004, doi: 10.1016/j.polymertesting.2004.04.012.

[21] S. Q. Liu, W. G. Gong, and B. C. Zheng, "The Effect of Peroxide CrossLinking on the Properties of Low-Density Polyethylene," Journal of Macromolecular Science, Part B, vol. 53, no. 1, pp. 67-77, Jan. 2014, doi: 10.1080/00222348.2013.789360.

[22] A. K. Sen, B. Mukherjee, A. S. Bhattacharyya, L. K. Sanghi, P. P. De, and A. K. Bhowmick, "Effect of cross-linking on the crystallization and fusion behaviour of polyethylene-ethylene propylene diene terpolymer blends," Thermochimica Acta, vol. 157, no. 1, pp. 45-59, Jan. 1990, doi: 10.1016/0040-6031(90)80005-J.

[23] M. D. H. Beg, S. Kormin, M. Bijarimi, and H. U. Zaman, "Preparation and Characterization of Low-Density Polyethylene/Thermoplastic Starch Composites," Advances in Polymer Technology, vol. 35, no. 1, 2016, doi: 10.1002/adv.21521.

[24] A. S. Alghamdi, "Synthesis and Mechanical Characterization of High Density Polyethylene/Graphene Nanocomposites," Engineering, Technology \& Applied Science Research, vol. 8, no. 2, pp. 2814-2817, Apr. 2018.

[25] R. Kotsilkova, D. Fragiadakis, and P. Pissis, "Reinforcement effect of carbon nanofillers in an epoxy resin system: Rheology, molecular dynamics, and mechanical studies," Journal of Polymer Science Part B: Polymer Physics, vol. 43, no. 5, pp. 522-533, 2005, doi: 10.1002/polb.20352.

[26] J. Gu, H. Xu, and C. Wu, "The Effect of PP and Peroxide on the Properties and Morphology of HDPE and HDPE/PP Blends," Advances in Polymer Technology, vol. 32, no. 1, 2013, doi: 10.1002/adv.21326. 